\section{Optimalisasi Potongan Plat Besi dengan Mesin Las Otomatis}

\section{Dimas Fredy Arisandy ${ }^{1}$ Rasional Sitepu ${ }^{2}$, Andrew Joewono ${ }^{3}$}

${ }^{1}$ Tenaga R\&D industri material manufaktur, PT Dwi Gading Wijaya Mandiri, Surabaya, dan Mahasiswa PSPPI di Fakultas Teknik, UnikaWidya Mandala Surabaya.

2,3Pengajar di Jurusan Teknik Elektro dan PSPPI Fakultas Teknik, Unika Widya Mandala Surabaya.

andrew_sby@ukwms.ac.id
Dalam bidang manufaktur banyak digunakan material plat besi. Pada PT. Dwi Gading Wijaya Mandiri plat besi sebagai bahan baku utama dalam pembuatan produk, seperti bakrak sorong, tutup diesel untuk molen, tabung molen semen dan cover perontok padi. Dalam proses pemotongan plat digunakan mesin CNC plasma untuk mendapatkan hasil yang presisi dan juga cepat. Setiap pemotongan plat terdapat plat sisa yang tidak dapat digunakan kembali dengan mesin plasma karena ukuran terlalu kecil, sehingga plat besisisa tersebut tidak dapat digunakan kembali dalam proses produksi. Banyaknya material sisa menyebabkan kurang efisiensi penggunaan material, sehingga menimbulkan kerugian produksi. Untuk menyelesaikan masalah tersebut, dibuatlah mesin penyambung plat dengan pengelesan otomatis. Pada mesinpenyambung plat otomatis ini memiliki beberapa komponen penting, yaitu panel kontrol untuk melakukan proses pengambilan data input dari tombol dan sensor serta melakukan pengaktifan aktuator. Solenoid valve dan pneumatic silinder sebagai penahan plat saat dilakukan pengelasan yang bertujuan untuk menghindari pemuaian plat saat dilakukan pengelasan. Motor dc 24 volt sebagai penggerak torch las saat melakukan pengelasan pada plat. Rangkaian PWM yang berfungsi untuk melakukan pengaturan kecepatan motor torch saat melakukan pengelasan. Sensor proximity induktif memberikan inputan untuk mengaktifkan dan menonaktifkan mesin las dan Mesin las Mig Techweld 50oW. Pembuatan mesin las penyambung plat otomatis terbukti dapat mengolah kembali plat sisa pemotongan, sehingga mengurangi kerugian akibat sisa material yang tidak terpakai.

Kata kunci: pemuaian, mesin las, kerugian produksi

Dipresentasikan: 30 Agustus 2019

Direvisi: 14 September 2019

Diterima: 2 Oktober 2019

Dipublikasikan online: 5 Oktober 2019

\section{Pendahuluan}

Dalam bidang manufaktur material yang sering kali digunakan adalah plat besi. Pada PT. Dwi Gading Wijaya Mandiri, Surabaya, plat besi adalah bahan baku utama dalam pembuatan produk, seperti bak rak sorong, tutup disel untuk molen, tabung molen semen dan cover perontok padi. Dalam proses pemotongan plat digunakan mesin CNC plasma untuk mendapatkan hasil yang presisi dan juga cepat. pada sekali pemotongan plat terdapat banyak sekali plat sisa yang tidak dapat di potong kembali dengan mesin plasma karena ukuran yang tidak sesuai dengan dimensi meja plasma, sehingga plat besi sisa tersebut tidak dapat digunakan kembali dalam proses produksi.

Untuk mengoptimalkan bahan sisa tersebut plat besi sisa akan disatukan dengan menggunakan mesin las, tetapi terjadi masalah saat menyatukan plat besi tersebut salah satunya adalah plat yang dilas bengkok sehingga tidak dapat dipotong oleh mesin plasma. Pada studi kasus kali ini bertujuan mencari solusi agar plat sisa pemotongan plasma dapat dimanfaatkan kembali agar tidak terjadi kerugian material.

Tujuan pembahasan ini untuk optimalisasi plat besi:

1. Mengatasi masalah kerugian produksi karena terbuangnya material sisa.

2. Menemukan solusi untuk agar sisa potongan plat dapat digunakan kembali dan dapat dipotong dengan mesin plasma

3. Menemukan solusi agar tidak terjadi pemuaian material saat dilakukan pengelasan.

Untuk mencapai tujuan tersebut dibuatlah mesin yang dapat menyambung plat sisa secara otomatis dan dapat menjaga agar plat tidak terjadi pemuaian.

\section{Metode}

Pada mesin penyambung plat otomatis ini memiliki beberapa komponen penting, yaitu panel kontrol untuk melakukan proses pengambilan data input dari tombol dan

Cara mensitasi artikel ini:

Arisandy, D.F., Sitepu, R., Joewono, A. (2019) Optimalisasi Potongan Plat Besi dengan Mesin Las Otomatis. [Edisi Khusus].

Buletin Profesi Insinyur 2(3): 115-117 
sensor serta melakukan pengaktifan aktuator. Solenoid valve dan pneumatik silinder sebagai penahan plat saat dilakukan pengelasan yang bertujuan untuk menghindari pemuaian plat saat dilakukan pengelasan. Motor dc 24 volt sebagai penggerak torch las saat melakukan pengelasan pada plat. Rangkaian PWM yang berfungsi untuk melakukan pengaturan kecepatan motor torch saat melakukan pengelasan. Sensor proximity induktif untuk memberikan inputan untuk mengaktifkan dan menonaktifkan mesin las dan Mesin las mig techweld 500W. Berikut adalah bagianbagian mesin las plat otomatis.

Panel switch adalah kumpulan dari swtitch yang disusun sedemikian rupa untuk memberikan inputan berupa tegangan ke bagian kontroler. Panel switch ini menggunakan 16 switch push on dan 1 konektor kabel db25 sebagai konetor penghubung kabel dari panel switch ke panel kontrol. seperti pada Gambar 1.

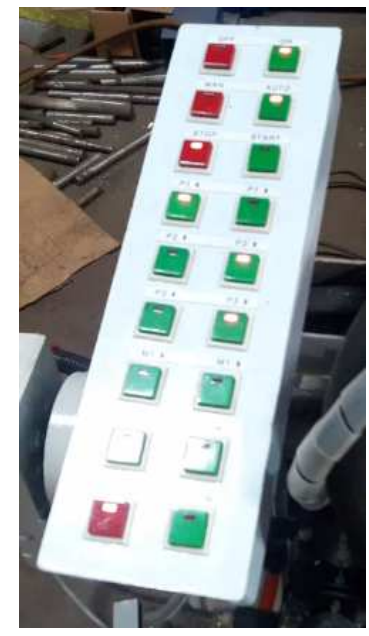

Gambar 1. Panel Switch

Mesin las otomatis ini menggunakan modul PWM 10A untuk melakukan pengaturan kecepatan motor saat proses pengelasan. Pada mesin ini, digunakan dua PWM modul untuk mengatur kecepatan motor torch turun dan mengatur kecepatan motor las seperti pada Gambar 2.

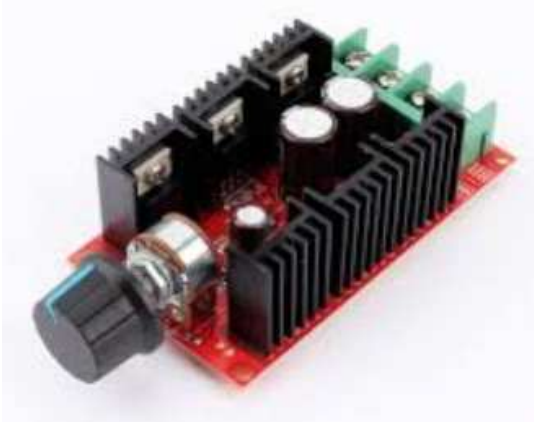

Gambar 2. Modul PWM

Dalam proses pengelasan menggunakan mesin las MIG merk Techweld dengan kapasitas 500W. Las mig menggunakan elektroda bertipe mild steel dengan diameter $1.2 \mathrm{~mm}$. Kelebihan las mig ini diantaranya dapat melakukan pengelasan lebih cepat tanpa perlu mengganti elektroda secara terus menerus. Las MIG ini juga menggunakan gas $\mathrm{CO} 2$ (inert) sebagai pelindung logam las yang mencair untuk menghindari terjadinya lubang saat pengelasan. seperti pada Gambar 3.

Solenoid valve adalah katup yang digerakkan oleh energi listrik melalui solenoida, mempunyai kumparan sebagai penggeraknya yang berfungsi untuk menggerakan piston yang dapat digerakan oleh arus AC maupun DC. Solenoid valve pneumatic atau katup (valve) solenoida mempunyai lubang keluaran, lubang masukan dan lubang exhaust. Lubang masukan, berfungsi sebagai terminal/tempat udara bertekanan masuk atau supply (service unit). Sedangkan lubang keluaran berfungsi sebagai terminal atau tempat tekanan angin keluar yang dihubungkan ke pneumatic. Lubang exhaust berfungsi sebagai saluran untuk mengeluarkan udara bertekanan yang terjebak saat plunger bergerak atau pindah posisi ketika solenoid valve pneumatic bekerja seperti pada Gambar 4.

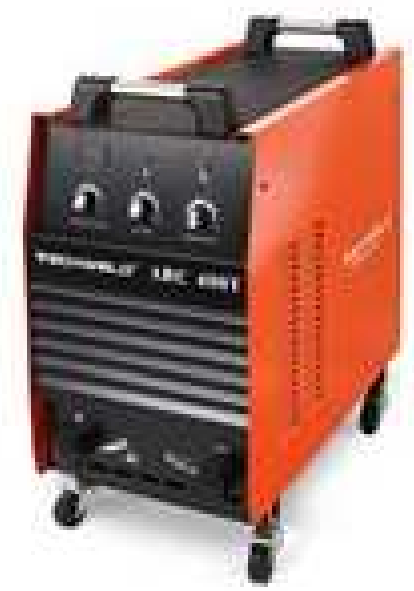

Gambar 3. Mesin Las Mig

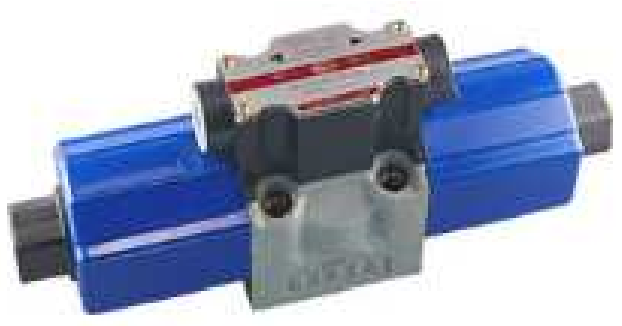

Gambar 4. Solenoid

\section{Hasil Kerja/Analisa}

Pembuatan mesin las penyambung plat otomatis terbukti dapat mengolah kembali plat sisa pemotongan mesin plasma, sehingga mengurangi kerugian akibat sisa material yang tidak terpakai. Mesin ini juga dapat 
melakukan pengelasan secara otomatis tanpa menimbulkan pemuaian plat karena panas yang dihasilkan mesin las. Gambar 5 dan 6 adalah gambar masing-masing tampak depan mesin las otomatis dan gambar mesin saat proses pengelasan.

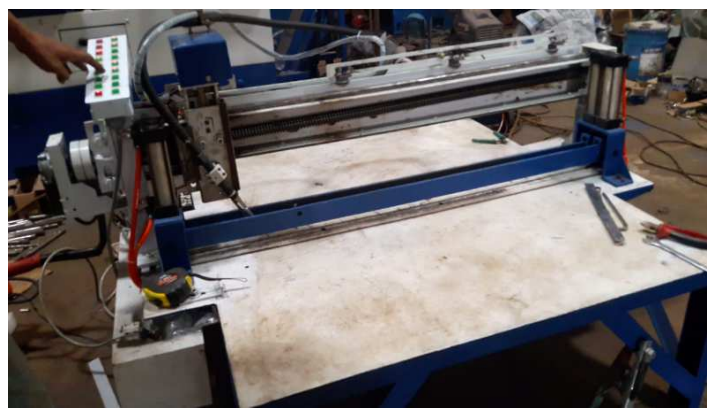

Gambar 5. Tampak Depan Mesin Las Otomatis

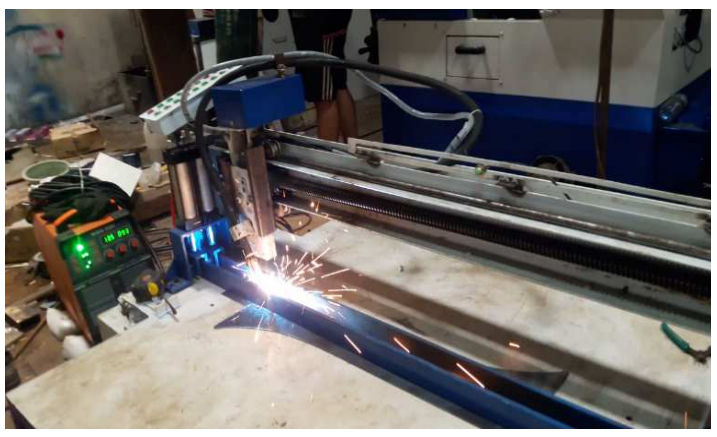

Gambar 6. Mesin Saat Proses Pengelasan

\section{Kesimpulan}

Dari hasil uji coba mesin las didapat kesimpulan sebagai berikut:

1. Dengan menggunakan mesin las plat otomatis ini tidak terjadi pembengkokan material setelah melakukan pengelasan.

2. Plat yang telah disambung dapat dipotong kembali dengan mesin plasma, sehingga tidak banyak material sisa yang terbuang.

\section{Ucapan Terimakasih}

Ucapan terima kasih ditujukan kepada :

1. Para dosen pengajar di PSPPI Fakultas Teknik Unika Widya Mandala Surabaya

2. Pimpinan PT Dwi Gading Wijaya Mandiri, Surabaya

3. Staff workshop R\&D, Margomulyo, PT Dwi Gading Wijaya Mandiri Surabaya

\section{Referensi}

Trifianto, D.A. Membandingkan Kinerja Macam - Macam Proses Pengelasan Manual Dalam Aplikasi Produksi, (Widyaiswara Muda - PPPPTK/BOE Malang)

Akbar, T., Santosa, B. (2015) Analisa Pengaruh dari Welding Sequence Terhadap Tegangan Sisa dan Deformasi Pada Circular Patch Weld Double Bevel Butt-Joint Plat ASTM A36Menggunakan Metode Element Hingga, Jurnal Teknik ITS Vol. 1, No. 1 ISSN: 2301-9271

Diktat Las MIG Teknik Pengelasan, http://staff.uny.ac.id/sites/default/files/MIG.pdf 